University of Louisville

ThinkIR: The University of Louisville's Institutional Repository

Electronic Theses and Dissertations

$5-2014$

\title{
Preventive effect of non-mitogenic acidic fibroblast growth factor on diabetes-induced testicular cell death.
}

Melissa Skibba 1990-

University of Louisville

Follow this and additional works at: https://ir.library.louisville.edu/etd

Part of the Pharmacy and Pharmaceutical Sciences Commons

\section{Recommended Citation}

Skibba, Melissa 1990-, "Preventive effect of non-mitogenic acidic fibroblast growth factor on diabetesinduced testicular cell death." (2014). Electronic Theses and Dissertations. Paper 1337.

https://doi.org/10.18297/etd/1337

This Master's Thesis is brought to you for free and open access by ThinkIR: The University of Louisville's Institutional Repository. It has been accepted for inclusion in Electronic Theses and Dissertations by an authorized administrator of ThinkIR: The University of Louisville's Institutional Repository. This title appears here courtesy of the author, who has retained all other copyrights. For more information, please contact thinkir@louisville.edu. 


\title{
PREVENTIVE EFFECT OF NON-MITOGENIC ACIDIC FIBROBLAST GROWTH FACTOR ON DIABETES- INDUCED TESTICULAR CELL DEATH
}

\author{
By \\ Melissa Skibba \\ B.S., Carroll University, 2012
}

\begin{abstract}
A Thesis
Submitted to the Faculty of the

School of Medicine of the University of Louisville

In Partial Fulfillment of the Requirements

for the Degree of
\end{abstract}

Master of Science

Department of Pharmacology and Toxicology

University of Louisville

Louisville, Kentucky

May, 2014 



\section{PREVENTIVE EFFECT OF NON-MITOGENIC ACIDIC FIBROBLAST GROWTH FACTOR ON DIABETES-INDUCED TESTICULAR CELL DEATH \\ By \\ Melissa Skibba \\ B.S., Carroll University, 2012}

A Thesis Approved on
April 10, 2014
by the following Thesis or Dissertation Committee:

Lu Cai, M.D., Ph.D.

Zhao-Hui Song, Ph.D.

Wenke Feng, Ph.D.

Paul Epstein, Ph.D.

Chi Li, Ph.D. 


\section{ACKNOWLEDGEMENTS}

I would like to thank my mentor, Dr. Lu Cai, for his guidance and for expanding my knowledge in the field of diabetes. I would also like to thank my committee members, Dr. Zhao-Hui Song, Dr. Wenke Feng, Dr. Paul Epstein, and Dr. Chi Li for their valuable feedback and assistance. A special thanks to Chi Zhang, Xin Jiang, Ying Xin, and the rest of the Cai lab for making my time in the lab enjoyable and for helping me when I needed it. Lastly, I want to thank my family for their support and encouragement. 


\section{ABSTRACT \\ PREVENTIVE EFFECT OF NON-MITOGENIC ACIDIC FIBROBLAST GROWTH FACTOR ON DIABETES-INDUCED TESTICULAR CELL DEATH}

Melissa Skibba

April 10, 2014

Fibroblast growth factor (FGF)-1 was found to protect the heart from oxidative damage, but clinically its long-term use was restricted for its undesirable proliferating activity on cells. Thus a cluster of amino acids responsible for the proliferation were deleted in the native FGF-1 to create a non-mitogenic FGF-1 (nmFGF-1). To assess whether nmFGF-1 protects male germ cells from diabetes-induced apoptotic death, the study employed a murine model of diabetes using multiple low-doses of streptozotocin, followed by nmFGF-1 treatment for 6 months. Diabetic mice showed a decrease in testicular weight and an increase in apoptotic cell death. Treatment with nmFGF-1 alleviated diabetic effects on testicular weight and apoptotic cell death. Mechanistically, nmFGF-1 alleviated diabetes-induced germ cell death by decreasing the BAX/Bcl-2 ratio, endoplasmic reticulum stress and associated cell death. Our results suggest that nmFGF-1 application prevents apoptotic cell death in testes of diabetic mice from mediation which was associated with Nrf-2 and AKT activation. 


\section{TABLE OF CONTENTS}

PAGE

ACKNOWLEDGEMENTS .......................................... iii

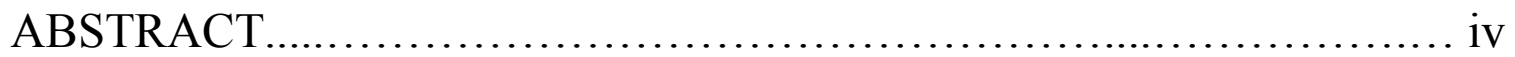

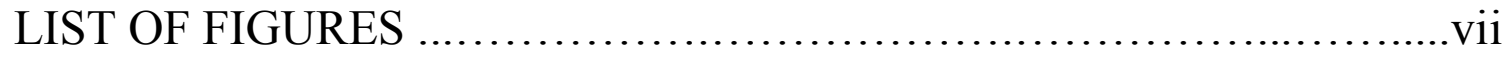

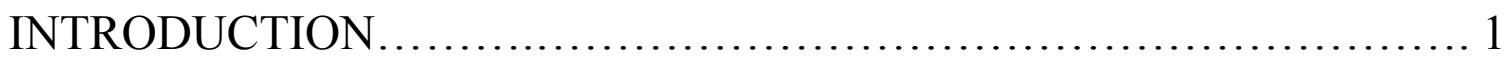

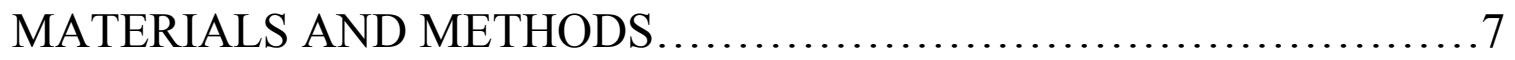

Animal and Diabetes Model.....................................................

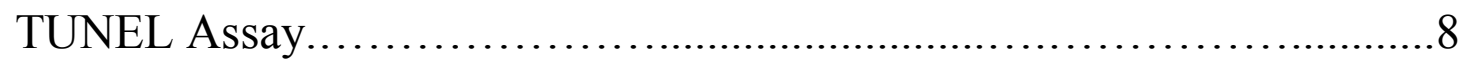

Immunohistochemical Staining ........................................ 9

Western Blot.............................................................10

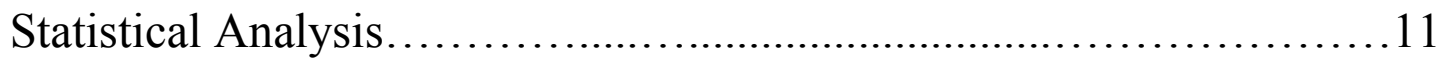

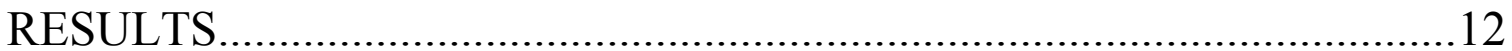

Evaluation of nmFGF-1 capacity of stimulating cell proliferation in the

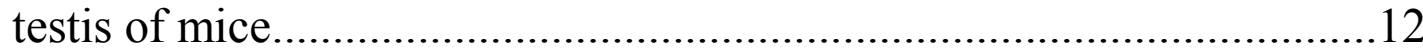

Protection by nmFGF-1 from diabetes-induced testicular shrinkage.....12

Protection by nmFGF-1 from diabetes-induced apoptosis....................12

The protection by nmFGF-1 from diabetes-induced receptor cell death

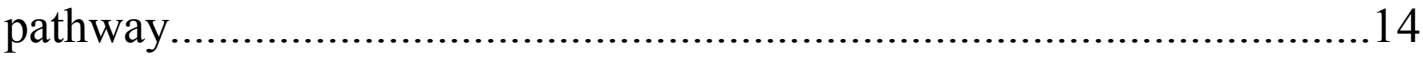

The protection by nmFGF-1 from diabetes-induced oxidative stress.....15

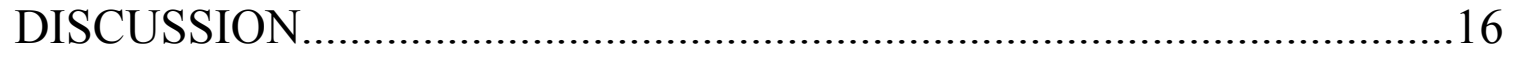


PAGE

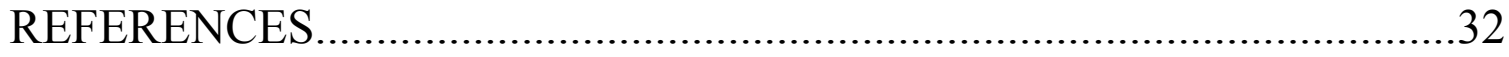

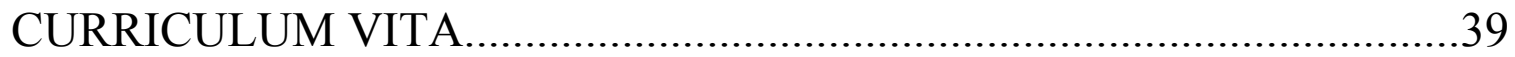




\section{LIST OF FIGURES}

FIGURE

PAGE

1. Evaluation of nmFGF-1 cell proliferation effect on the testis of diabetic mice 21

2. Evaluation of testes weight 22

3. Effect of nmFGF-1 on diabetes-induced testicular apoptosis

4. Immunohistochemical evaluation of nmFGF-1 on diabetes-induced mitochondrial associated apoptotic pathway.

5. Western blot assay evaluation of nmFGF-1 on diabetes-induced mitochondrial associated apoptotic pathway

6. Effect of nmFGF-1 on diabetes-induced ER stress associated apoptotic pathway.

7. Effect of nmFGF-1 on diabetes-induced ER stress associated apoptotic pathway

8. Effect of nmFGF-1 on diabetes-induced TNF- $\alpha$ and caspase-8 activation

9. Effect of nmFGF-1 on diabetes-induced oxidative stress .29

10. Effect of nmFGF-1 on diabetes-induced testicular antioxidants.

11. Illustration of the working mechanisms for nmFGF-1 prevention of diabetes-induced germ cell apoptosis. 


\section{CHAPTER I}

\section{INTRODUCTION}

\section{Diabetes}

Diabetes is a global health concern and over the years, the number of those diagnosed with diabetes continues to increase. Diabetic complications include cardiovascular disease, neuropathy, retinopathy, nephropathy, and hypoglycemia.

There are two types of diabetes [1]: Type 1 (T1DM) and Type 2 (T2DM). The former is due to lack of insulin generated from $\beta$-cells in the pancreas and the latter is characterized by insulin resistance causing a lack of insulin secretion. Although T2DM is the main proportion at about $90 \%$, the disease occurs at the relatively late period of life (after 40 years old) [1]; however, T1DM is diagnosed mostly in children and young adults. It is known that males with diabetes can experience a decrease in testicular size, low testosterone levels, and testicular dysfunction; all result in infertility which is a common complication in diabetic men [2]. Several mechanisms have been proposed to relate infertility of men with diabetes. For instance, about $35-75 \%$ of males with diabetes develop autonomic neuropathy, leading to a loss of penile erection and retrograde ejaculation $[3,4]$. In addition, the autonomic neuropathy induced by diabetes causes an

abnormally testicular sensation and vascular reflexes [4]. Testicular ischemia, imbalance of glucose metabolism and improper lipid storage can cause testicular cell death leading to germ cell loss; an important cause for the infertility of diabetic men. 


\section{Spermatogenesis}

The testis, as the male gonad in mammals, forms part of the male reproductive system. Testes are components of both the reproductive system and the endocrine system. Spermatogenesis occurs within the seminiferous tubules of the testis. It is divided into three distinct phases: (a) spermatogonia proliferate, giving rise to spermatocytes; (b) spermatocytes go through two meiotic divisions, leading to the formation of spermatids;

(c) spermatids go through extensive morphological remodeling, producing highly differentiated spermatozoa. In addition, spermatozoa continue to undergo a maturation process as they transit through various regions of the seminiferous epithelia within the seminiferous tubule. Germ cells at different developmental stages in the seminiferous epithelium possess their own distinct physiological features and respond differently to toxic stimuli such as ischemia. The complex process of spermatogenesis is orchestrated by adjacent Sertoli cells that support the maturation process by providing nutrition, hormones, and other mediators [5-8]. Sertoli cells also maintain the architectural and functional integrity of the seminiferous epithelium by mediating phagocytosis of germ cells that have died in the vicinity, predominantly via apoptosis [9-11]. Therefore, diabetes may affect the function of the endocrine cells in the male reproductive system (Leydig and Sertolic cells) and the spermatogenesis of germ cells (spermatogonia, spermatocytes, spermatids, and spermatozoon), leading to apoptotic cell death of these cells, the germ cells primarily.

\section{Apoptosis}

Apoptosis refers to programmed cell death triggered by various signals to remove unwanted cells during development, protect host cells, and prevent autoimmunity [12]. 
Signals are mediated by proteases which are activated by zymogens via three major mechanisms. The extrinsic and intrinsic pathways are the two major pathways and use an energy-dependent cascade to activate their own initiator caspase, but use effector caspases, such as caspase-3, as the end caspase for apoptosis [13]. The intrinsic pathway (e.g., p53 pathway) also uses non-receptor stimuli to produce intercellular signals that act directly on its targets [13]. Apoptotic damage caused by diabetes, has been observed in several types of organs to strongly be related to the mitochondrial pathways regulated by Bax, Bcl-2, and Bak and the endoplasmic reticulum pathway using caspase-12 and CHOP; all categorized under the intrinsic pathway. The third mechanism is the granzyme pathway which works in a caspase-independent fashion. Apoptosis then utilizes an execution pathway to exhibit the normal apoptosis characteristics of chromatic condensation, cell shrinkage, apoptotic bodies and phagocytosis [13].

Apoptotic effect of diabetes on the testes has not been investigated extensively, and only a few apoptotic mechanisms have been identified thus far. The characterization of apoptosis in male germ cells can be uniquely identified by cellular swelling and decondensed-homogeneous chromatin, but also exhibit the classical morphology of apoptosis [14]. Age can also play a part in influencing the extent of apoptosis. Extensive studies in mice have shown that young individuals have a high incidence of apoptotic cell death in the testis compared to adults. This can be explained by the role of apoptosis to eliminate overproduced, abnormal, or damaged germ cells during the time spermatogonia undergo mitotic divisions [14]. To maintain genomic stability for DNA replication and repair, p53 regulates gene transcription by activating apoptosis [14]. The extrinsic pathway uses a cellular transmembrane protein, to also regulate germ cell apoptosis when 
FasL binds to the Fas receptor forming the "death-inducing signaling complex." However, Fas signaling is not required for germ cell apoptosis because when mutations were made to FasL and Fas, germ-cell apoptosis was not blocked [14]. This is due to the Bax signaling pathway inducing the apoptosis which then feeds into the Fas pathway. This was supported in experiments by Bozec et al. using wild-type mice to indicate that initiation of apoptosis is followed by cytoplasmic to paranuclear localization redistribution of pro-apoptotic Bax protein in germ cells [15].

Germ cells are unique in that different stress situations activate distinct apoptotic cell death pathways. For example, for temperature-related stress, mitochondrial pathway is important for heat-induced germ cell death, but hypothermia activates both the mitochondrial and endoplasmic reticulum pathways $[17,18]$. We have demonstrated that diabetes predominantly induces testicular apoptotic cell death through mitochondrial and endoplasmic reticulum (ER) stress associated cell death pathways. This is caused by proapoptotic factors and the glycation of end products to activate the caspase signaling and oxidative stress [19-21]. Several fibroblast growth factors (FGFs) were also found to play certain roles in diabetes-induced testicular germ cell death.

\section{Fibroblast Growth Factors (FGFs)}

The FGF family consists of 22 mammalian members that have shown to be important in regulating tissue patterning and organogenesis of several reproductive organs, including the testis. Primarily, the FGFs that are important in organogenesis are the paracrine factors including FGF-1-10, 16-18, 20, and 22; however, the endocrine factors comprising of FGF19, 21, and 23 can also be used to maintain normal spermatogenesis and protect from apoptosis [22]. 
FGF-1 and FGF-2 were the first two FGFs characterized and are identical in 55\% of their amino acids [23]. Both are paracrine factors that have mitogenic activity and are expressed in embryogenesis during differentiation. Laslett et al. examined Leydig cell steroidogenesis and the effects of FGF-1 and FGF-2 using 5-, 21-, and 90-day-old rats [24]. The results of the experiments demonstrated that both FGF-1 and FGF-2 had stimulatory effects on basal LH-stimulated testosterone production. The increased testosterone production was caused by fetal Leydig cells and basal $5 \alpha$-androstane$3 \alpha, 17 \beta$-diol production in immature Leydig cells [24].

All members of the FGF family are known to contain a heparin/heparin sulfatebinding domain but only for some are these domains essential for their biological effect. FGF-1 and FGF-2 lack signal sequences to export out of cell using classical secretory pathways thus they use other ways to get exported [25]. FGF-1 uses a heat stimulus to export via the extravesicular protein synaptotagmin, while FGF-2 is released under situations of cell death [25]. Once exported, the FGFs are able to bind to heparin sulfate proteoglycans in the extracellular matrix [25]. This allows FGF-1 and FGF-2 to stimulate blood vessel growth for angiogenesis which can be useful in wound healing, but these FGFs are highly expressed in tumorigenic patients due to their proliferative nature which may aid in tumor growth. FGF-2 primarily stimulates the proliferation and migration of lymphatic and vascular endothelial cells to down regulate Ras-JNK signaling [22]. Whereas FGF-1 activates MMP-1 for endothelial cell migration and facilitates angiogenesis, FGF-1 also stimulates MMP-9 which is expressed in breast cancer cells to accelerate tumor invasion and metastasis [22]. 
FGF-1 is distinctive from other FGF paracrine factors because it is considered "endocrine-like" in that it can act like a vasodilator, neuromodulator, and has been shown to protect the brain and heart from ischemic reperfusion [26-28]. FGF-1 also has the ability to stimulate blood vessel ingrowth for angiogenesis, useful in wound healing, which has been extensively supported by previous studies that showed FGF-1 to reverse diabetic wound healing in rats with skin lesions through increased cell proliferation [29, 30]. Diabetes is highly associated with neuropathy and ischemia in various organs throughout the body including the testes. FGF-1 is known as a potential treatment for ischemia and neuropathy in the heart and spinal cord [28], but has not yet been investigated to treat diabetic complications in the testes.

The present study was to examine the effect of FGF-1 on diabetic hyperglycemia in the testes to prevent oxidative stress associated cell death. However, FGF-1 usage as an in vivo application has been unsuccessful in that the excessive proliferative nature of native FGF-1 may lead a tumorigenic risk, thus a non-mitogenic form (nmFGF-1) was developed by deletion of the part responsible for the mitogenic function [31]. To explore whether chronic application of nmFGF-1, without undesirable long-term mitogenic effects can protect male germ cells from apoptosis caused by diabetes, we used multiple low-dose injections of streptozotocin (STZ) in FVB mice to induce a type-1 diabetes model. Diabetic and age-matched control mice were treated with and without nmFGF-1 for 6 months. Its protective effect on diabetes-induced testicular cell death and potentially underlying mechanisms were examined. 


\section{CHAPTER II}

\section{MATERIAL AND METHODS}

\section{Animals and diabetes model}

All mice were housed in the University of Louisville Research Resources Center at $22{ }^{\circ} \mathrm{C}$ with a 12 -h light/dark cycle with free access to food and tap water. All procedures were approved by Institutional Animal Care and Use Committee, which is certified by the American Association for Accreditation of Laboratory Animal Care. Eight weeks old male FVB mice were randomly divided into four groups: control (CON), diabetes (DM), nmFGF-1 treated control (nmFGF-1), and diabetes treated with nmFGF-1 (nmFGF-1+DM). To make the type-1 diabetes model, STZ (Sigma-Aldrich, St. Louis, MO) was dissolved in $0.1 \mathrm{M}$ sodium citrate ( $\mathrm{pH} 4.5)$ and given intraperitoneally to the mice with five daily doses of $50 \mathrm{mg} / \mathrm{kg}$ body weight. Corresponding control mice were given the same volume of sodium citrate buffer. Whole blood glucose levels were determined using mouse tail vein blood at 5 days after the last STZ injection. Mice with blood glucose level $\geq 250 \mathrm{mg} / \mathrm{dl}$ were considered diabetic. The $\mathrm{nmFGF}-1$ was provided by Xiaoping Wu from Jinan University in which he amplified the plasmid pUC-nmFGF-1 by a standard polymerase chain reaction with the appropriate primers to eliminate the $\mathrm{N}$ terminal residues 1-27, purified, and transformed into E. coli strain BL21 [31]. The mice in the nmFGF-1 groups were intraperitoneally injected with nmFGF-1 at $10 \mu \mathrm{g} / \mathrm{kg}$ body weight daily until sacrificed. All mice were sacrificed 6 months after start of nmFGF-1 treatment and testis tissue was harvested. 


\section{Terminal deoxynucleotidyl transferase-mediated dUTP nick end labeling (TUNEL)}

\section{Assay}

Testicular tissues were placed in a formalin solution for 2 days immediately after tissues were harvested from the mouse. The testicular tissue was then stored in an $80 \%$ ethanol solution until they were cut in half and exposed to $95 \%$ ethanol solution for $5 \mathrm{~h}$ and then another $95 \%$ ethanol solution overnight. The next day, the tissues were changed three times in 100\% ethanol for 40 min each before treatment of 1:1 solution of xylene and $100 \%$ ethanol for $30 \mathrm{~min}$. Then the tissues were put into four exchanges of dimethyl benzene for $20 \mathrm{~min}$ each. Following dimethyl benzene exposure, the tissues were transferred to three different liquid paraffin solutions for $40 \mathrm{~min}$ each. The paraffinized tissues were sectioned at $5 \mu \mathrm{m}$ and embedded on slides with two groups each; CON (n=5) and DM (n=5); nmFGF-1 $(\mathrm{n}=4)$ and nmFGF-1 + DM $(\mathrm{n}=5)$.

The sections were deparaffinized using two washings of xylene followed by rehydration using two solutions of $100 \%$ ethanol for 5 min each and then exposure to $95 \%$ and $75 \%$ ethanol for 3 min each. A minimum of 3 testes from different mice were used in each group and stained for TUNEL with the ApopTag Peroxidase In Situ Apoptosis Detection Kit (Chemicon, Temecula, CA). Each slide was deparaffinized and rehydrated, and treated with proteinase $\mathrm{K}(20 \mathrm{mg} / \mathrm{l})$ for $15 \mathrm{~min}$ at room temperature. Slides were treated with $3 \%$ hydrogen peroxide to quench endogenous peroxidases for 5 min, and then were incubated with TUNEL reaction mixture containing terminal deoxynucleotidyl transferase (TdT) and digoxigenin-11-dUTP at $37^{\circ} \mathrm{C}$ for $1 \mathrm{~h}$. Then 3,3diaminobenzidine chromogen was applied. Methyl green was used as counterstaining. Under the microscope, apoptotic cells exhibited brown nuclear staining as the TUNEL 
positive and were quantitatively counted manually from at least 3 animals per group. The apoptotic cells were counted from spermatogonia, primary spermatocytes, and secondary spermatocytes, but not spermatid and spermatozoa. Results were presented as TUNEL positive cells divided by total number of seminiferous tubule cross sections to give an average per tubule and then multiplied by 100 for the total number of TUNEL positive cells in 100 tubules.

\section{Immunohistochemical staining}

Testicular tissues fixed in 10\% neutral-buffered formalin were embedded in paraffin and sectioned at $5 \mu \mathrm{m}$ as described in TUNEL staining. The sections were deparaffinized in xylene and rehydrated in graded alcohol solutions as explained in TUNEL staining. After sections were incubated with retrieval solution (Dako, Carpinteria, CA) for $15 \mathrm{~min}$ at $98{ }^{\circ} \mathrm{C}$ and then treated with $3 \%$ hydrogen peroxide for 15 min at room temperature, samples were blocked with 5\% BSA for $1 \mathrm{~h}$. A minimum of 3 testes per group were incubated with primary antibodies including anti-proliferating cell nuclear antigen (PCNA, 1:2000 dilution, Cell Signaling, Danvers, MA), Bax (1:200, Cell Signaling), Bcl-2 (1:200, Cell Signaling), and anti-4-hydroxy-2-nonenal (4-HNE, 1:200, Alpha Diagnostic International, San Antonio, TX) at $4^{\circ} \mathrm{C}$ overnight. After washing with PBS, these sections were incubated with horseradish peroxidase conjugated secondary antibody for $1 \mathrm{~h}$ at room temperature. For the development of positive cells, a brown color was created when peroxidase substrate 3,3-Diaminobenzidine was used (Vector Laboratories Inc., Burlingame, CA) and then hematoxylin was used as counterstaining. Quantification for PCNA, Bax, and Bcl-2 were counted manually. Results were presented as positive cells divided by total number of seminiferous tubules to give an average per 
tubule and then multiplied by 100 as described above for TUNEL studies. Quantification for 4-HNE was performed using the Image-Pro Plus 6.0 software, and presented as the fold of control for the integrated optical density (IOD), reporting the average intensity/density of each DAB-stained region.

\section{Western blot}

Protein extraction was first performed by homogenizing the testicular tissue from each group, CON (n=5), nmFGF-1 $(n=5), D M(n=4)$ and nmFGF-1 + DM $(n=4)$, in RIPA lysis buffer (Santa Cruz Biotechnology, Santa Cruz, CA) followed by centrifugation at $2000 \mathrm{RPM}$ for $1 \mathrm{~min}$. The samples were oscillated for $4 \mathrm{~h}$ and at $12000 \mathrm{RPM}$ for $15 \mathrm{~min}$ to separate the purified protein solution which was used for the western blot assay. The protein concentration was calculated using a standard curve determined from detection of protein samples after Bio-Rad Protein Assay Dye Reagent Concentrate (Life Science, Hercules, CA) was added using a plate reader spectrophotometer at 595 absorbance.

The samples were prepared at the proper concentration using calculations from the plate reader with dilution in lysis buffer. Dithiothreitol (Sigma Aldrich, St Louis, MO) and loading buffer were added to the protein solution and heated at $95{ }^{\circ} \mathrm{C}$ for $5 \mathrm{~min}$, followed by separation on 10\% SDS-PAGE electrophoresis and transferred to a nitrocellulose membrane. The membrane was blocked with 5\% non-fat milk for $1 \mathrm{~h}$, and incubated overnight at $4{ }^{\circ} \mathrm{C}$ with the following primary antibodies: Bax, Bcl-2, cleaved caspase-12, CHOP (Gadd), BiP (GRP78), and total AKT (all 1:1000 dilution and from Cell Signaling) as well as phospho-AKT (Ser473) and cleaved caspase-8 (all 1:500 dilution and from Cell Signaling), TNF- $\alpha$ (1:500 dilution, Abcam, Cambridge, MA), ATF-4 (1:100 dilution, Abcam), Anti-Nrf2 (phospho at S40) (1:3000 dilution, Abcam), 
Nrf2 (H-300) (1:3000, Santa Cruz Biotechnology), SOD2 and Catalase (1:5,000 dilution, Santa Cruz Biotechnology) and anti- $\beta$-actin (1:2000 dilution, Santa Cruz Biotechnology).

The unbound antibodies were removed and the membranes were incubated with the horseradish peroxidase-conjugated secondary antibody for $1 \mathrm{~h}$ at room temperature. Specific bands were visualized using an enhanced chemi-luminescence detection kit (ECL, Thermo Scientific, Vernon Hills, IL). Quantitative densitometry was performed on the identified bands by using Image Quant 5.2 software.

\section{Statistical analysis}

Data was presented as mean \pm S.D. ( $\mathrm{n}>3$ per group). Comparisons were performed by one-way ANOVA for the different groups, followed by Tukey's test with Origin 7.5 software. Statistical significance was considered as $\mathrm{p}<0.05$. 


\section{CHAPTER III}

\section{RESULTS}

\section{Evaluation of nmFGF-1 capacity to stimulate cell proliferation in the testis of mice}

The nmFGF-1 was created without the mitogenic effects on the tissue by suppressing the proliferative nature of native FGF-1 [31]; therefore, the testicular cell proliferation was evaluated by immunohistochemical staining using PCNA. PCNA staining demonstrated nmFGF-1 did not increase the testicular cell proliferation compared to the control mice $(\mathrm{CON})$ that were injected with a sodium citrate buffer (Fig. 1). After 6-months onset type-1 diabetes caused by STZ injections, the diabetic mice (DM) showed a significant increase in testicular PCNA-positive cells while nmFGF-1 treatment $(\mathrm{nmFGF}-1+\mathrm{DM})$ prevented the significant increase in the testicular PCNApositive cells in diabetic mice (Fig. 1).

\section{Protection by nmFGF-1 from diabetes-induced testicular shrinkage}

Although there were some fluctuations in the diabetic mouse body weight gain (Fig. 2A), there were no difference for tibia lengthening (Fig. 2B) among groups. Therefore the testis weight was normalized with tibia length in each mouse (Fig. 2C). The nmFGF-1 group matched with the control while diabetic mice showed a significant decrease in the ratio of testis weight to tibia length at the 6th month after the onset of diabetes, consistent with previous studies [21], which was prevented by nmFGF-1 treatment in the diabetic mice (Fig. 2C). However, diabetic mice treated with nmFGF-1 
had a significantly lower testicular weight compared to the control and non-diabetic nmFGF-1 mice (Fig. 2C).

\section{Protection by nmFGF-1 from diabetes-induced apoptosis}

Previous studies have demonstrated that diabetes induces apoptosis via both mitochondrial and ER pathways in the testes [21]. Induction of apoptosis was observed, by TUNEL staining, in diabetic mice 6 months after diabetes onset due to a significant increase in TUNEL-positive cells compared to control and nmFGF-1 groups (Fig. 3). Chronic treatment of nmFGF-1 significantly decreased the number of TUNEL-positive cells in diabetic mice. The TUNEL-positive cells were primarily in the spermatogonia and spermatocytes (Fig. 3).

Using immunohistochemical staining (Fig. 4) and Western blot assay (Fig. 5A), an increase in Bax/Bcl-2 ratios was shown in mouse testes of diabetic mice, suggesting that the diabetes model is related to the mitochondrial cell death pathway.

Immunohistochemical staining shows when diabetic mice are treated with nmFGF-1, there is a decrease in the $\mathrm{Bax} / \mathrm{Bcl}-2$ ratio compared to control and diabetic mice (Fig.4). When we looked that the Bax/Bcl-2 ratio using protein expression through Western blot assay, we observed that the increase in the ratio was predominantly due to the decrease in Bcl-2 in diabetic mice (Fig.5A), whereas the diabetic mice treated with nmFGF-1 caused a decrease in the ratio compared to the diabetic mice due to a suppression of Bax (Fig. 5A).

The decrease in Bax can be related to the function of an increased AKT causing an inhibitory action on Bax. Using the Western blot assay, it was shown that nmFGF-1 increased the phosphorylated to total AKT ratio significantly in both the nmFGF-1 and 
diabetic mice treated with nmFGF-1 compared to control (Fig. 5B). Diabetic mice showed a decrease in the AKT ratio compared to nmFGF-1 group and the diabetic group treated with nmFGF-1 had an AKT ratio significantly higher than the diabetic mice (Fig. 5B).

Next we examined several indicators of ER stress; BiP, caspase-12, CHOP, and ATF-4 (Fig. 6 and 7) by Western blot assay. BiP (Fig. 6A) and CHOP (Fig. 7A) were significantly increased in the diabetic mice, as found in previous studies [21], compared to control and nmFGF-1, but the activation of caspase-12 (Fig. 6B) was significantly increased in the diabetic mice compared to nmFGF-1 mice. Treatment of diabetic mice with nmFGF-1 showed a significant decrease in ER stress, reflected by BiP (Fig. 6A), CHOP (Fig. 7A), and ATF-4 (Fig. 7B) expression compared to those of untreated diabetic mice. In addition, nmFGF-1 treated diabetic mice showed a decrease in ATF-4 compared to control and nmFGF-1 mice (Fig. 7B). There was no significant attenuation in caspase-12 activation in nmFGF-1-treated diabetic mice compared to untreated diabetic mice (Fig. 6B).

\section{The protection by nmFGF-1 from diabetes-induced receptor cell death pathway}

In previous studies of mice 4 months onset of diabetes and younger, diabetes was

shown to increase TNF- $\alpha$ and caspase-8 activation in the testes [21]. In the current study, the mice with 6 months onset diabetes also had a significant increase in TNF- $\alpha$ compared to control and nmFGF-1 groups (Fig. 8A), but no increase in caspase-8 activation (Fig. 8B) in the testis; suggesting that signal activation may be time dependent, where the signals had already occurred because cell death was already activated. The treatment with nmFGF-1 was able to significantly decrease TNF- $\alpha$ (Fig. 8A) and caspase- 8 activation 
(Fig. 8B) compared to diabetic mice, in addition, nmFGF-1 mice with and without diabetes also decreased cleaved-caspase-8 compared to control mice (Fig. 8A) leading to the conclusion that nmFGF-1 prevents the early cell death signaling to protect the testes from germ cell death.

\section{The protection by nmFGF-1 from diabetes-induced oxidative stress}

Diabetes is known to cause hyperglycemia that induces extra generation of reactive oxygen or nitrogen species (ROS and RNS) [32]. The body protects itself from extra ROS generation-mediated damage through multiple antioxidant pathways including the nuclear transcriptional factor (Nrf-2) pathway via increased antioxidant transcription. ROS interacts with Keap1 that binds Nrf-2, letting the Nrf-2 to be released from Keap1, allowing Nrf-2 to go into the nuclei activating antioxidant responsive elements (ARE); including superoxide dismutase 2 (SOD2) and catalase [32]. We demonstrated that diabetes increased oxidative damage as observed in 4-Hydroxynonenal (4-HNE) staining compared to all other groups (Fig. 9), and addition of nmFGF-1 resulted in no oxidative damage. Western blot data illustrated that the phosphorylated-Nrf-2/total-Nrf-2 ratio was decreased compared to the control and nmFGF-1, in mice with or without diabetes, was able to significantly increase phosphorylated-Nrf-2/total-Nrf-2 and SOD2 (Fig.10) compared to the control and diabetic mice, also Catalase expression was increased in diabetic mice treated with nmFGF-1 compared to all groups (Fig. 10). The data presents that nmFGF-1 uses Nrf-2 as protection from ROS that could lead to diabetes-induced apoptosis. 


\section{CHAPTER IV}

\section{DISCUSSION}

Numerous studies have demonstrated the damaging effects of diabetes-induced hyperglycemia on a variety of organs including the heart, kidney and even the liver, however diabetic testicular complications has not been explored until recent studies by our group [14, 19-21, 33]. It has been demonstrated that FGF-1 is protective in the heart and spinal cord, but its effect on diabetic testicular complications has not yet been examined.

Diabetes induces apoptotic germ cell death in the seminiferous epithelia of the testis. As it is shown in Fig. 2, six months after the onset of diabetes, the testes weight of diabetic mice significantly decreased with a significant increase in apoptotic death (Fig. 3). This trend was also present in previous studies with mice at 3 or 4 months after diabetes onset [19-21]. Diabetic mice also demonstrate increased proliferation (Fig.1) therefore the decrease in testicular weight proves that there is much more apoptotic cell death than growth, which is supported by increased apoptotic death as seen in the TUNEL staining (Fig. 3). What is unique is that nmFGF-1 was able to alleviate the apoptotic cell death caused by oxidative damage and significantly increase the testes weight without the excessive proliferation (Fig. 1), suggesting that nmFGF-1 mainly prevents diabetic induction of cell death, instead of promoting cell proliferation, as previously understood [24]. The decrease in proliferation in the nmFGF-1 mice models also indicate that the excessive proliferation from the native FGF-1 was obliterated. 
Apoptotic cell death caused by diabetes is evident through activation of both mitochondrial and ER cell signaling pathways [21, 33]. Both immunohistochemical staining (Fig. 4) and western blot assay (Fig. 5A) showed that diabetes decreased Bcl-2, a molecule important for cell survival. Contrary to diabetic mice which indicated a decrease in Bcl-2 caused an increase to the Bax/Bcl-2, nmFGF-1 didn't affect Bcl-2, but significantly decreased Bax, the pro-apoptotic mediator, as seen in Fig. 4 and 5A. The inhibitory effect of nmFGF-1 on Bax can be related to the protective nature of AKT [34]. It has been demonstrated that AKT inhibits Bax and subsequent cytochrome $\mathrm{c}$ release in the mitochondrial pathway for the prevention of apoptosis [34]. Therefore, the drastic increase in phosphorylated to total AKT ratio (Fig. 5B) in the nmFGF-1 diabetic and nondiabetic mice models is correlated to the depression in Bax. A decrease in Bax through the action of nmFGF-1 may also suggest the existence of cross-talk between ER and receptor cell death pathways; also noticed as two major pathways in diabetic germ cell death [33].

ER stress can trigger apoptosis in a mitochondrial-dependent or independent fashion, but previous studies suggested diabetes-induced ER stress via cross-talk within the intrinsic pathways [33]. Therefore, we used indicators of ER stress such as BiP, ATF4, CHOP and caspase-12 because these represent different ER stress pathways (Fig. 6 and 7). Cellular response to ER stress is mediated through three ER transmembrane receptors: pancreatic ER kinase (PKR)-like ER kinase (PERK), inositol-requiring enzyme 1, and activating transcription factor 6. PERK is the upstream receptor for activating ATF-4 and when there is an accumulation of unfolded proteins, BiP dissociates from the three ER transmembrane receptors, which leads to their activation and triggers the unfolded protein 
response [35]. However when there is an accumulation of aggregated proteins with continued stress, PERK converts it's function from being pro-survival to apoptotic [36], as observed in this study. Therefore, ATF-4 activates CHOP which is located within the ER and mediates programmed cell death by promoting protein synthesis and oxidative stress. In detecting stress from the diabetes condition, caspase-12 is used as a common indicator to sense ER stress due to low oxygen and glucose levels. Caspase-12 and CHOP have been strongly linked with their role in communication with the mitochondrial pathway [37-39]. Caspase-12 activation is linked to calcium efflux in the cytoplasm which activates m-calpain to induce the caspase system in ER stress [37]. The cause of the calcium efflux is believed to be caused by Bax causing a conformational change in the ER to induce the calcium efflux [38]. CHOP is also directly linked to the mitochondrial pathway by inhibiting Bcl-2 to induce apoptosis [39]. BiP (GRP78), cleaved caspase-12 and CHOP were increased in the diabetic model (Fig. 6 and 7A), supporting previous findings [33]. The nmFGF-1 was able to attenuate protein expression of BiP, CHOP, and ATF-4 (Fig. 6A, 7A and B), but not cleaved caspase-12 (Fig. 6B), suggesting that nmFGF-1 independently suppresses ER stress caused by diabetes. The cross-talk between the ER and mitochondrial pathways for apoptotic protection was not evident because nmFGF-1 reduced Bax in the mitochondrial pathway but did not increase Bcl-2 whereas in the ER pathway nmFGF-1 lessened CHOP and not caspase-12.

The death receptor pathway acts independent of the other pathways but also activates apoptosis-inducing factors in the mitochondria and ER. The upper arm TNF- $\alpha$, the activator of death receptor pathway and indicator of inflammation, will activate caspase- 8 leading to apoptosis. Caspase- 8 is important in that it can process Bid to 
activate Bax in the mitochondrial pathway to induce apoptosis and cleave B-cell receptor associated protein 31 to induce ER stress when there is apoptosis [40, 41]. In the present study, we observed that after 6 months diabetes onset, there was only an increase in TNF$\alpha$, but not cleaved caspase- 8 (Fig. 8). Therefore, we assume that caspase- 8 was activated prior to examination and that signal was no longer present due to substantial cell death via other pathways. The nmFGF-1 depressed protein expression of both TNF- $\alpha$ and cleaved caspase-8 (Fig. 8), suggesting nmFGF-1's action on caspase-8 pathway assisted in lowering the Bax/Bcl-ratio, relieving apoptosis in both the death receptor and mitochondrial pathways.

The cause of stress in the mitochondrial and ER cell signaling pathways can be traced to diabetes-induced hyperglycemia. Chronic hyperglycemia can cause an accumulation of ROS and/or NOS. ROS and/or NOS are then able to attack sites such as the mitochondria and ER which can cause a further release of ROS and/or RNS which leads to cellular damage. 4-HNE staining confirmed that there was an increased oxidative damage (Fig. 9) in the 6-month onset of diabetes mice, in agreement with the previous studies [33, 42]. Nrf-2 protects cells from oxidative or ER stress by entering the nucleus to activate multiple antioxidants; SOD2 and catalase. We found that nmFGF-1 significantly increased Nrf-2 phosphorylation, SOD2, and catalase expression (Fig. 10), indicating that nmFGF-1 may protect the testes from oxidative damage via the activation of Nrf-2 function.

In conclusion, native FGF-1 has been known as a vasodilator, neuromodulator, and stimulates angiogenesis using its highly proliferative nature but through this study we observed that FGF-1 can protect from oxidative stress in the testes caused by diabetic- 
hyperglycemia without the mitogenic effects using the nmFGF-1. Therefore, the prevention of testicular cell death under diabetic conditions by nmFGF-1 may be predominantly mediated by its prevention of apoptotic cell death, rather than stimulation of testicular cell proliferation. This is consistent with the finding that TUNEL staining along with the testes weight showed that nmFGF-1 had a preventative effect on diabetesinduced apoptosis and testis weight loss. For determining the predominant pathway in suppressing diabetes-induced apoptosis, we have examined the known pathways of diabetes induced cell death. Allowing us to conclude that nmFGF-1 may act on the mitochondrial pathway to suppress apoptosis through cross-talk with the cell death receptor pathway and AKT, in addition nmFGF-1 causes an independent suppression of ER stress. However, the nmFGF-1 may protect from diabetes-mediated oxidative damage through activation Nrf2, as outlined in the working hypothesis in Fig. 11. 


\section{FIGURES}

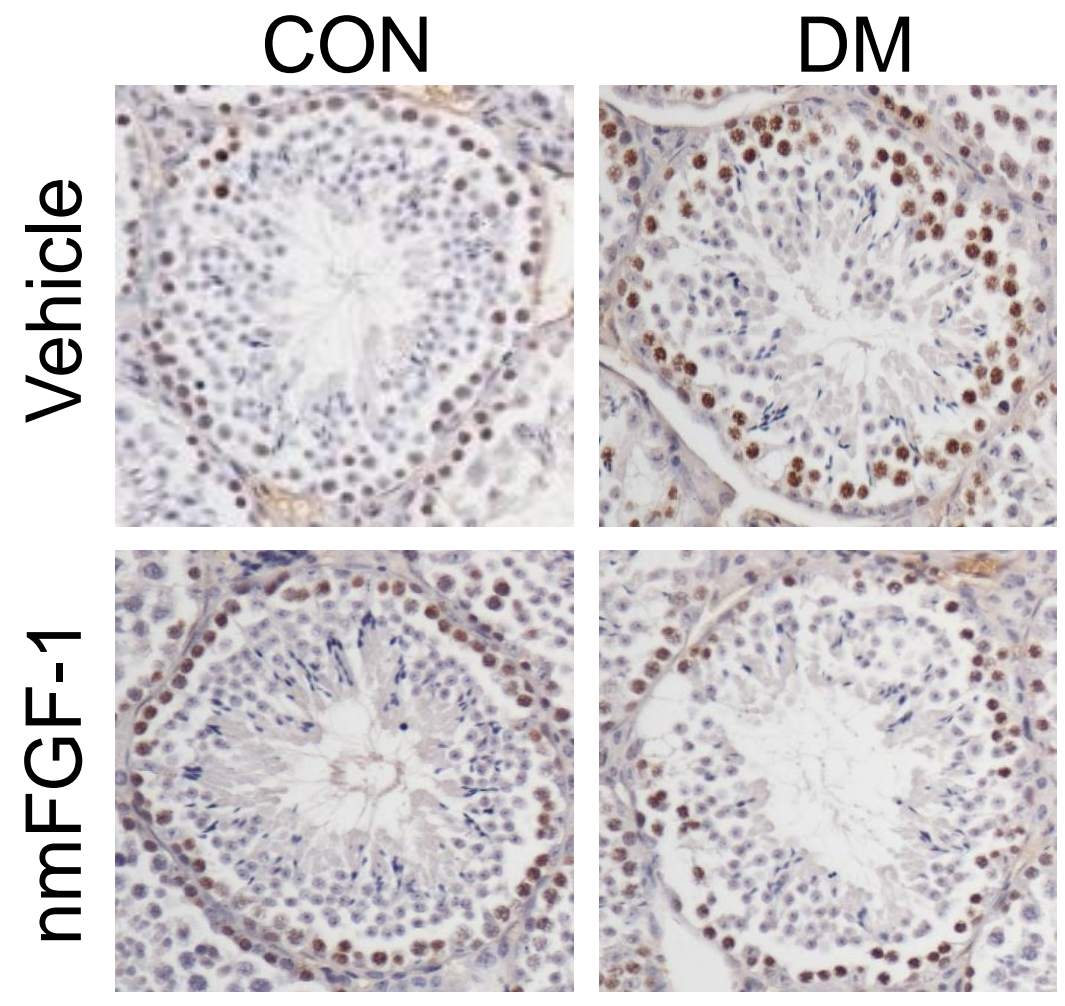

Figure 1. nmFGF-1 prevented cell proliferation in the testes of diabetic mice. PCNA immunohistochemical staining was used to show the positive (proliferative) nuclei of spermatogonia, primary and secondary spermatocytes. Positive cells were divided by number of tubules and multiplied by 100 to represent the number of PCNA per 100 tubules. Data is presented as mean \pm S.D. $(* p<0.05)$. 


\section{FIGURES}

A.

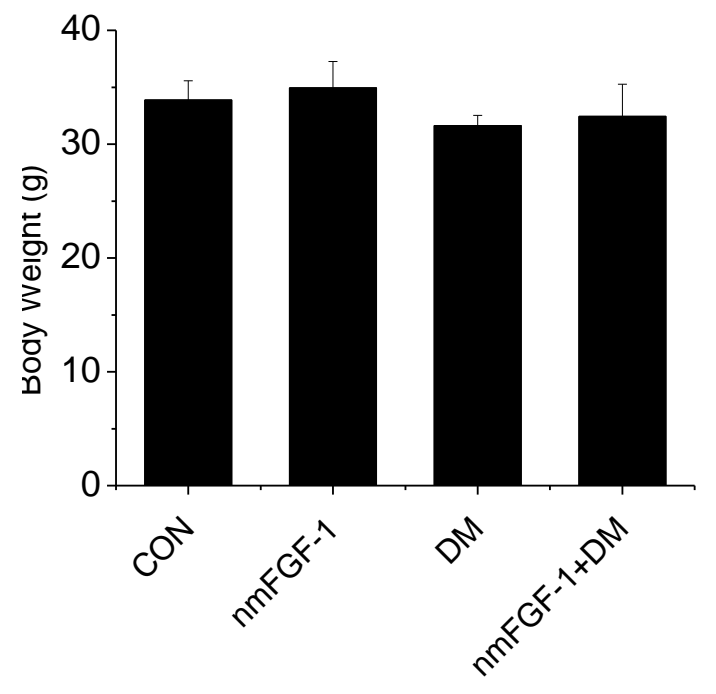

C.
B.

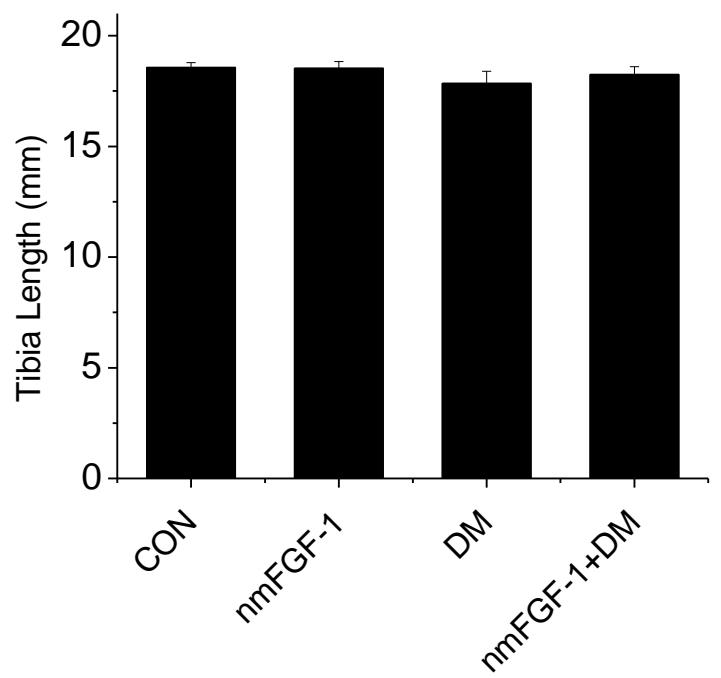

Figure 2. nmFGF-1 alleviated testicular weight loss in diabetic mice. The average body weight (g) of each mouse group (A) shown with the average tibia length (mm) (B). The testis/tibia $(\mathrm{mg} / \mathrm{mm})$ ratio $(\mathrm{C})$ was determined to exhibit the weight change of mouse testes in each group. Data is presented as mean \pm S.D. $(* p<0.05)$. 


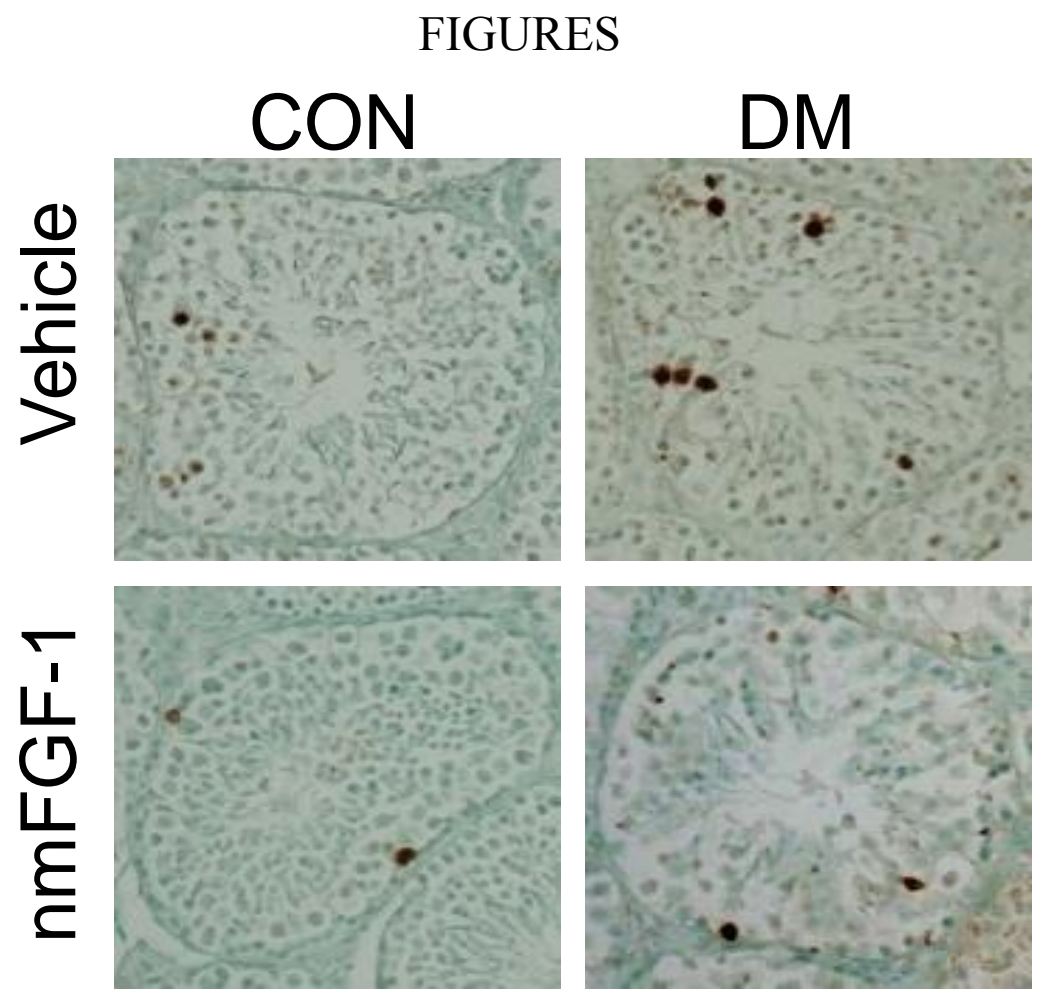

Figure 3. TUNEL staining of nmFGF-1 indicates reduced diabetes-induced testicular apoptosis. To measure the apoptosis in testis, TUNEL immunohistochemical staining was detected in nuclei of spermatogonia, primary and secondary spermatocytes. TUNEL positive cells were calculated and represented as described for PCNA in Fig. 1. Data is presented as mean \pm S.D. $(* \mathrm{p}<0.05)$. 


\section{FIGURES}

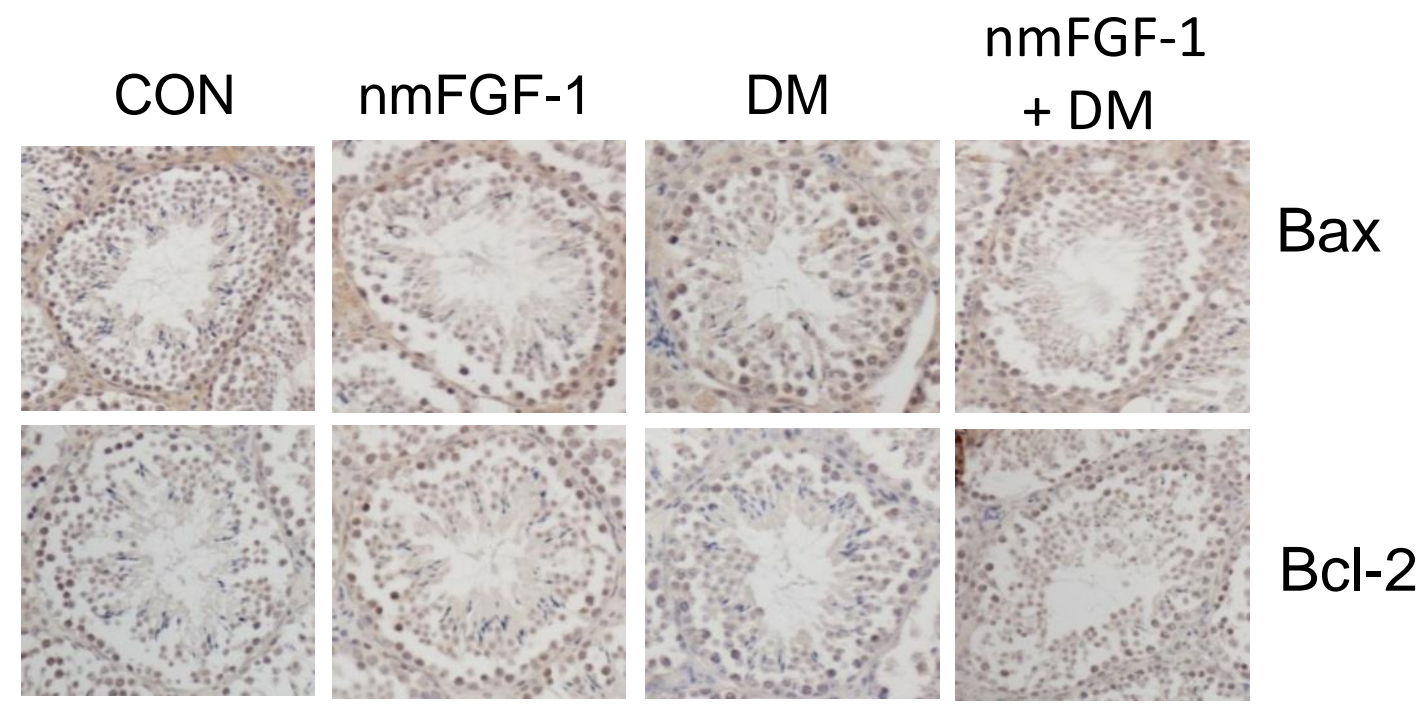

Figure 4. Immunohistochemical evaluation indicates nmFGF-1 prevents diabetesinduced mitochondrial associated apoptotic death. Immunohistochemical staining of Bax and Bcl-2 as well as the Bax/Bcl-2 ratio. Data is presented as mean \pm S.D. $(* \mathrm{p}<0.05)$. 


\section{FIGURES}

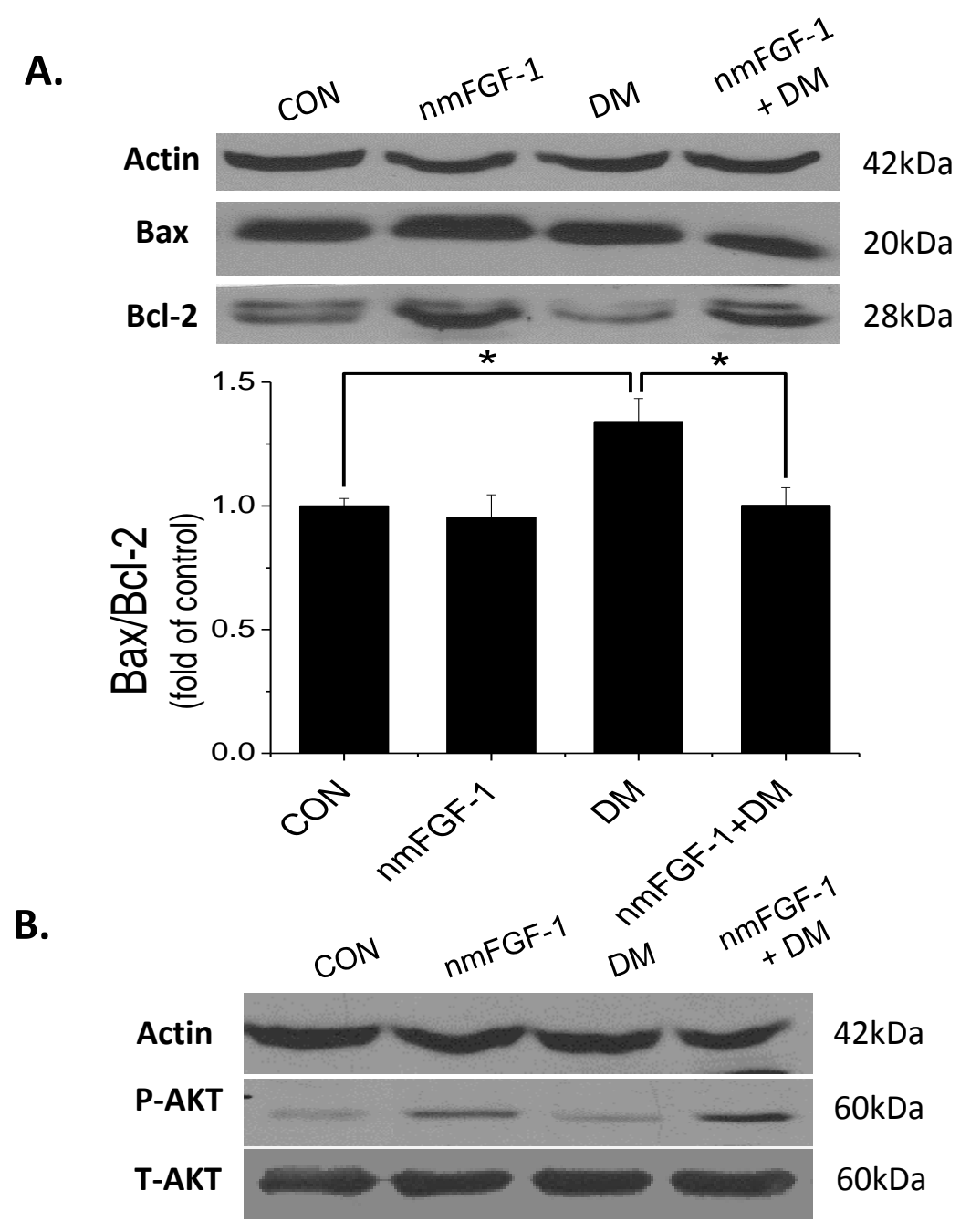

Figure 5. nmFGF-1 inhibits diabetes-induced mitochondrial associated apoptotic death due to AKT activation to inhibit Bax. Western blotting assay was used to confirm the expression of both Bax and Bcl-2 (A). Phosphorylated and total-AKT were determined using western blotting assay (B). Data is presented as mean \pm S.D. $(* p<0.05)$. 


\section{FIGURES}

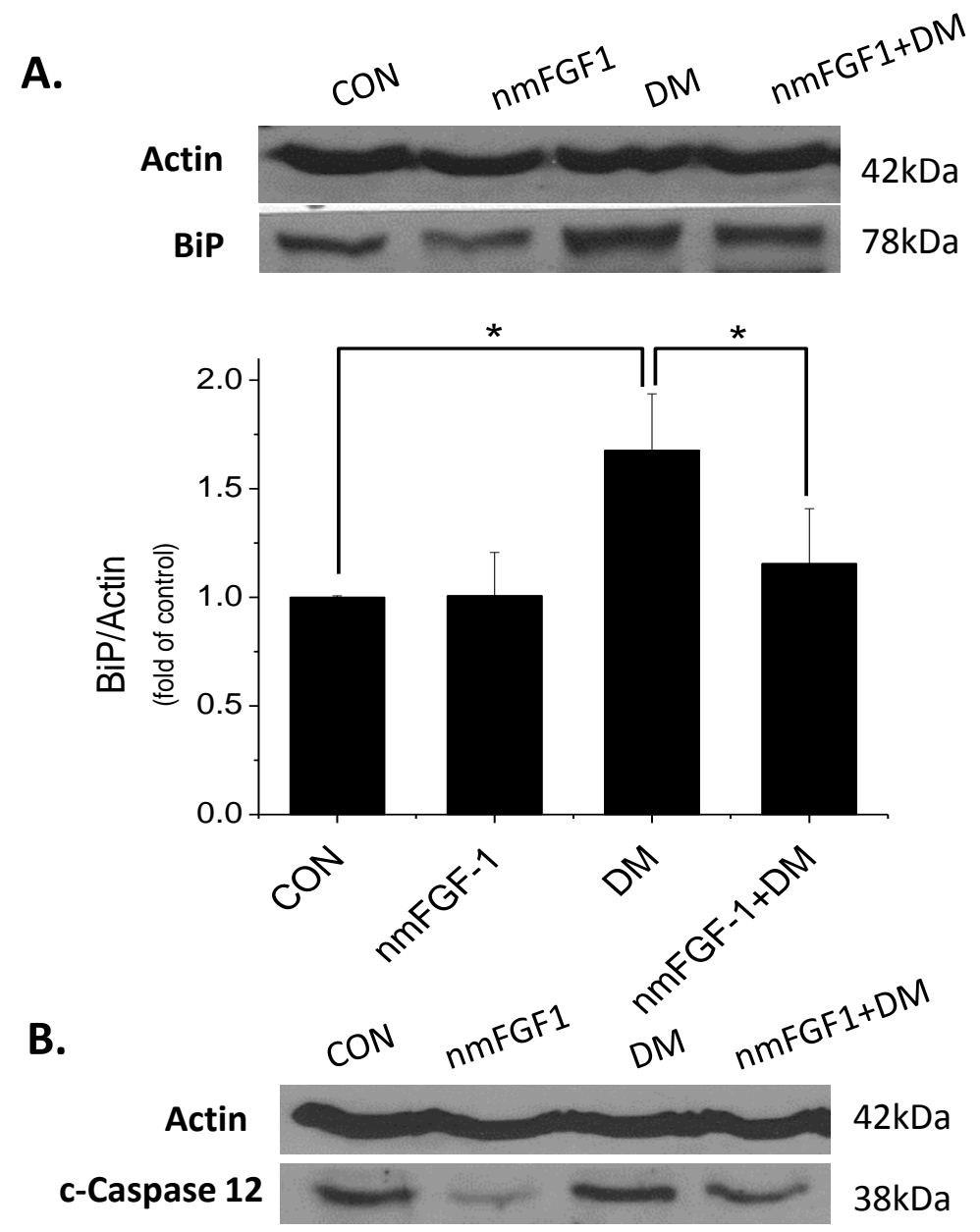

Figure 6. nmFGF-1 prevents diabetes-induced ER stress apoptotic death via downregulation of BiP. Western blotting assay was used to determine role of $\mathrm{BiP}(\mathrm{A})$ and cleaved caspase-12 (B) in the ER pathway. Data is presented as mean \pm S.D. $(* p<0.05)$. 


\section{FIGURES}

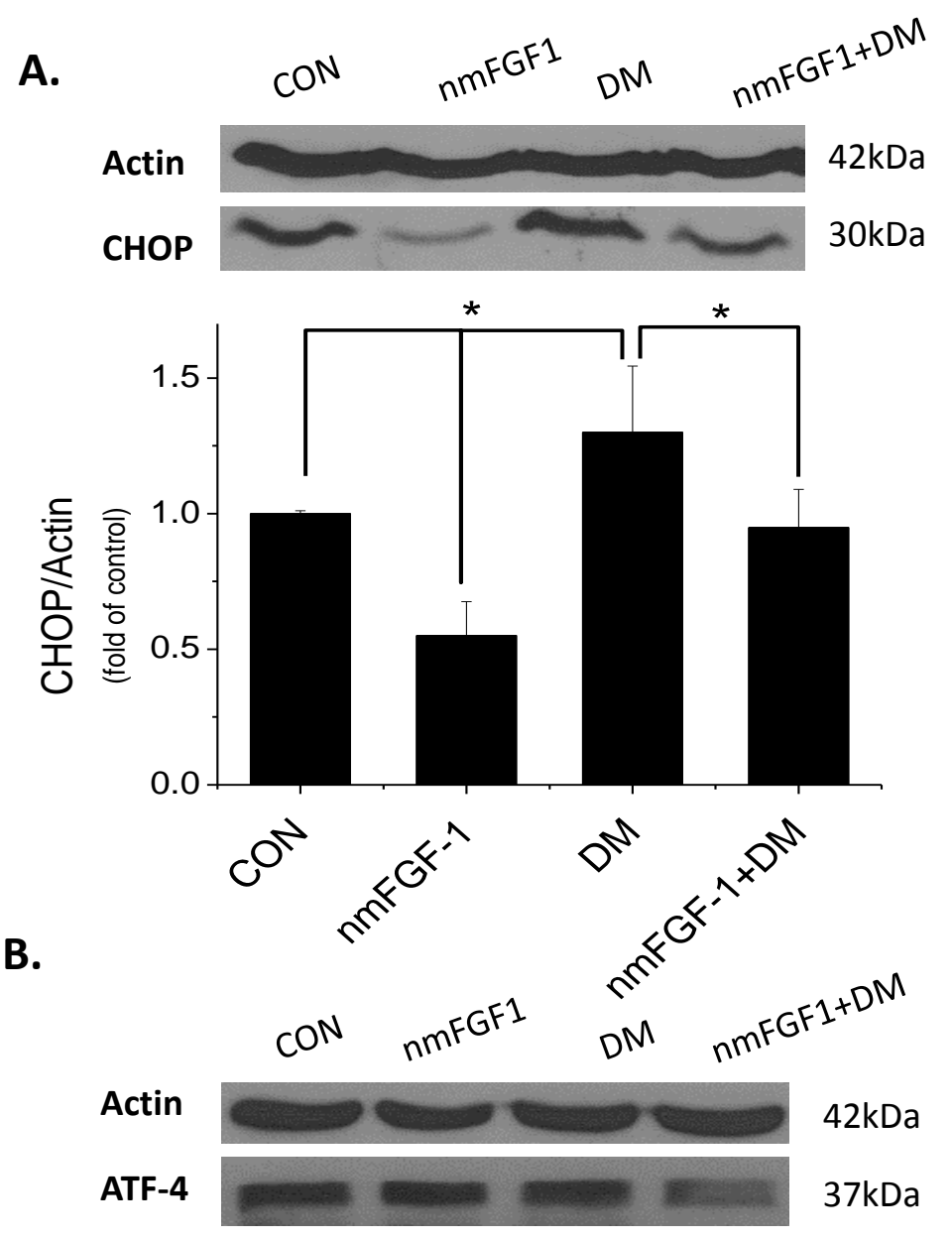

Figure 7. nmFGF-1 prevents diabetes-induced ER stress apoptotic death via downregulation of CHOP and ATF-4. Western blotting assay was used to determine role of CHOP (A) and ATF-4 (B) in the ER pathway. Data is presented as mean \pm S.D. (* $\mathrm{p}<0.05)$. 


\section{FIGURES}

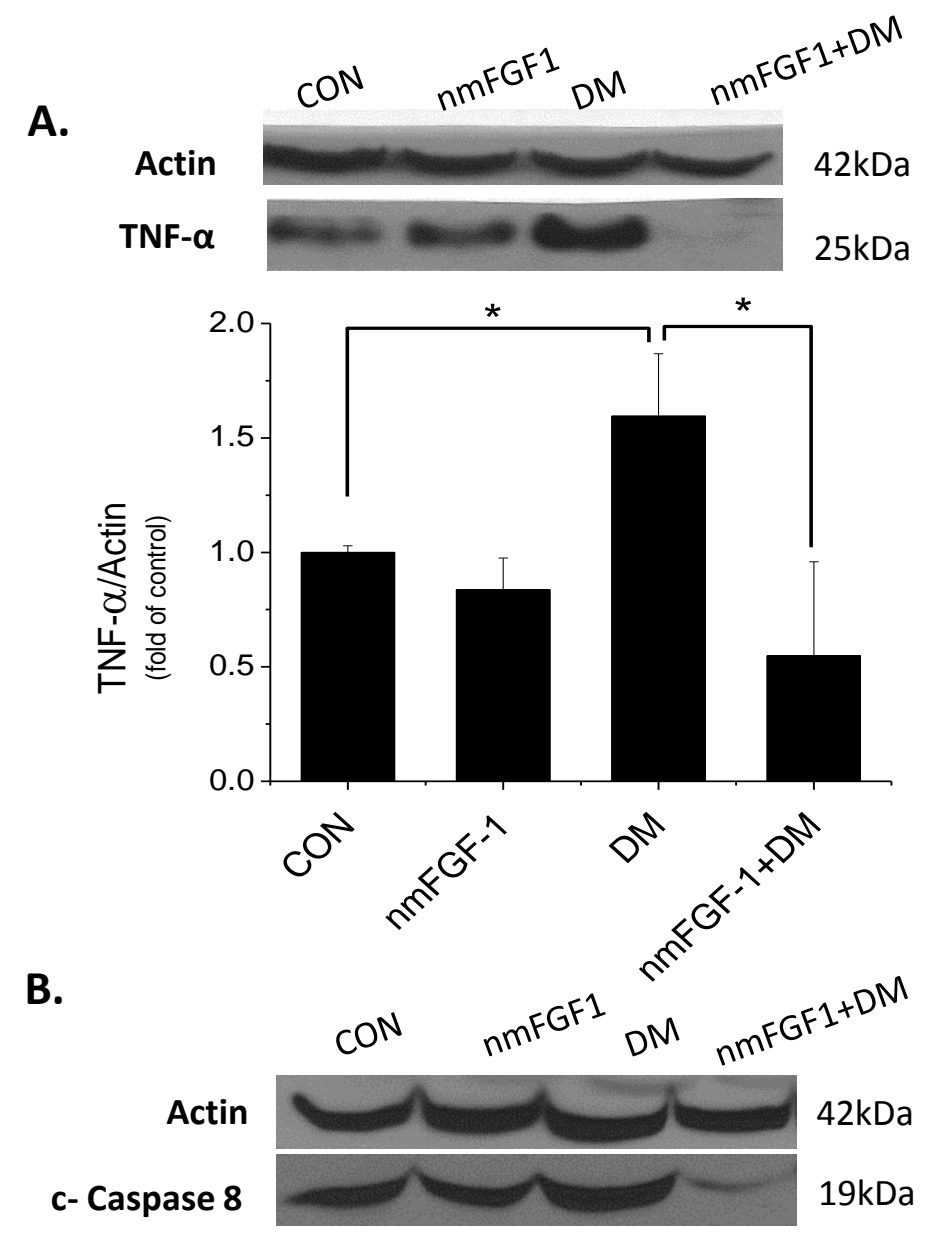

Figure 8. nmFGF-1 prevents diabetes-induced TNF- $\alpha$ and caspase-8 activation. Western blotting assay was used to determine TNF- $\alpha$ (A) and caspase- 8 cleavage (B). Data is presented as mean \pm S.D. $(* p<0.05)$. 


\section{FIGURES}

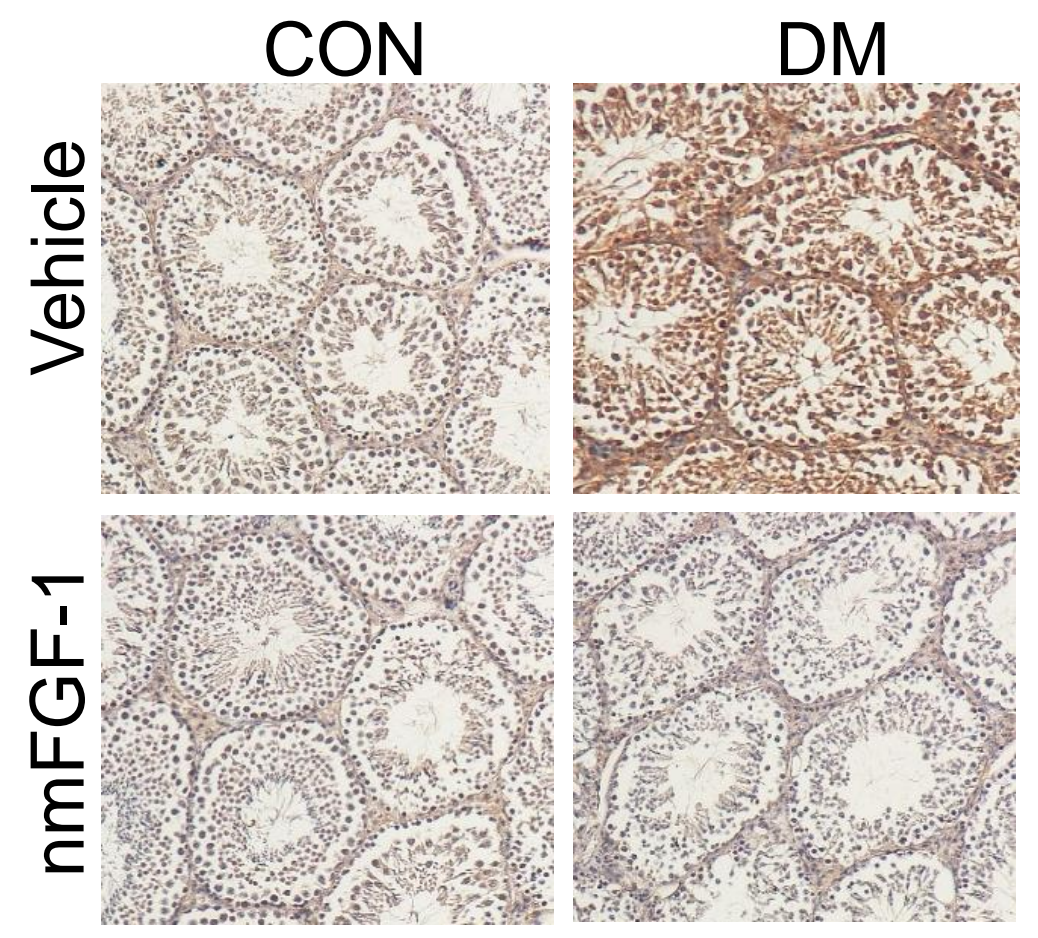

Figure 9. Immunohistochemical representation of nmFGF-1 to prevent diabetesinduced oxidative stress. Immunohistochemical staining of 4-HNE, followed by a semiquantitative analysis, showed a significant increase in 4-HNE accumulation. Data is presented as mean \pm S.D. $(* \mathrm{p}<0.05)$. 


\section{FIGURES}

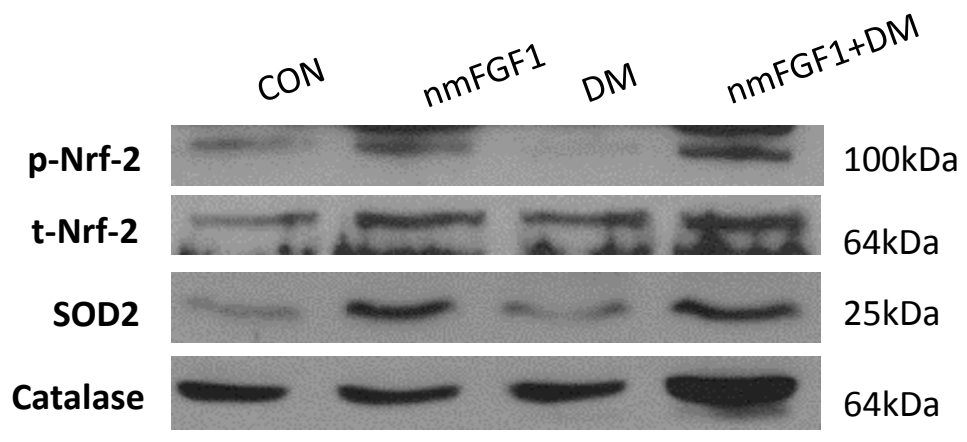

Figure 10. nmFGF-1 uses antioxidants to protect from diabetes-induced testicular oxidative stress. Western blotting assay shows the increase in phosphorylated-Nrf 2 to total-Nrf-2 and its downstream gene expression; SOD2 and catalase. Data is presented as mean \pm S.D. $(* \mathrm{p}<0.05)$. 


\section{FIGURES}

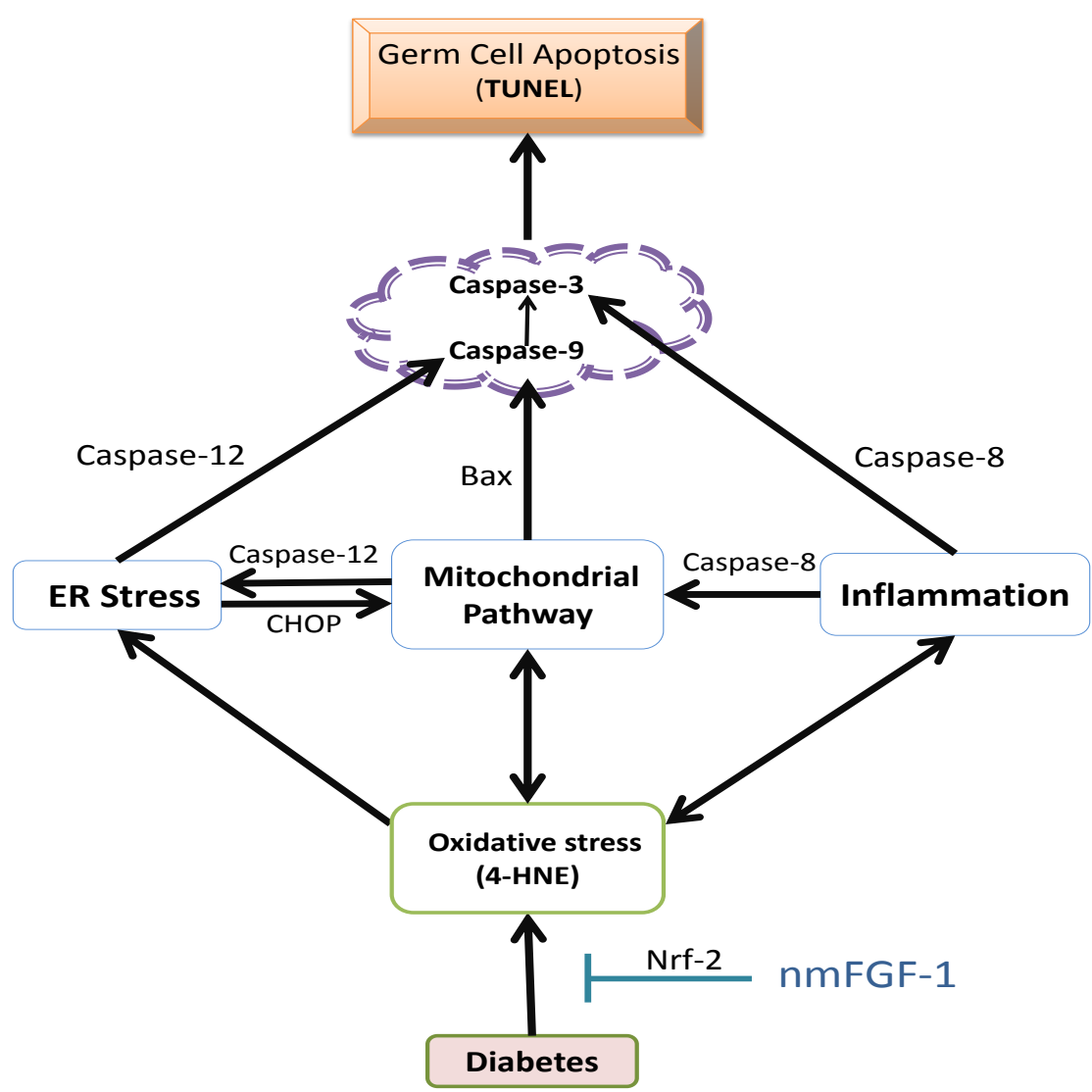

Figure. 11. Illustration of the working mechanisms for nmFGF-1 prevention of diabetes-induced germ cell apoptosis. Schematic illustration indicates that diabetes triggers oxidative damage (such as 4-HNE) due to hyperglycemic induction of ROS and/or RNS. The oxidative damage creates ER stress (BiP, CHOP and caspase-12), mitochondrial damage (Bax/Bcl-2), and inflammation (TNF- $\alpha$ and Caspase-8). Most of the oxidative damage goes back to the mitochondrial pathway through several signaling pathways for which the damaged mitochondrial pathway releases ROS or causes apoptosis. CHOP doesn't go through the caspase system but cross-talks with the mitochondrial pathway by inhibiting Bcl-2 [43]. When Bcl-2 is suppressed, there is an increase in Bax, the mitochondrial apoptosis-induced channel opens to allow cytochrome c release from mitochondrion to activate apoptotic protease activating factor-1 which then binds to pro-caspase- 9 to activate it and then activated caspase- 9 cleaves caspase- 3 to initiate apoptosis [44], as seen by TUNEL staining. Caspase-12 is thought to be activated by Bax due to calcium efflux in the cytoplasm which activates m-calpain switching on the caspase system to activated caspase-9 [45]. Finally, oxidative damage leads to inflammation and inflammation that can cause oxidative damage. When there is inflammation, TNF- $\alpha$ interacts with its receptor and activates caspase- 8 that in turn can directly activate caspase- 3 for apoptosis or can process Bid to activate Bax. The nmFGF-1 is thought to block apoptosis through the initial step of inhibiting oxidative damage; therefore, nmFGF-1 can block ER stress, the mitochondrial pathway and inflammation. Caspase-9 and 3 are in a "dashed" cloud because these were not examined in this study, but were extensively approved in previous studies. 


\section{REFERENCES}

[1] Centers for Disease Control and Prevention. National diabetes fact sheet: national estimates and general information on diabetes and prediabetes in the United States, 2011.

[2] Sexton WJ, Jarow JP. Effect of diabetes mellitus upon male reproductive function. Urology. 1997; 49(4):508-513.

[3] McCulloch DK, Campbell IW, Wu FC, Prescott RJ, Clarke BF. The prevalence of diabetic impotence. Diabetologia. 1980;18(4): 279-83.

[4] Campbell IW, Ewing DJ, Clarke BF, Duncan LJ. Testicular pain sensation in diabetic autonomic neuropathy. Br Med J. 1974;2(5920): 638-9.

[5] Bartke A. Apoptosis of male germ cells, a generalized or a cell type-specific phenomenon? Endocrinology. 1995;136(1): 3-4.

[6] Rodriguez I, Ody C, Araki K, Garcia I, Vassalli P. An early and massive wave of germinal cell apoptosis is required for the development of functional spermatogenesis. EMBO J. 1997; 16(9): 2262-2270.

[7] Blanco-Rodriguez J, Martinez-Garcia C. Spontaneous germ cell death in the testis of the adult rat takes the form of apoptosis: re-evaluation of cell types that exhibit the ability to die during spermatogenesis. Cell Prolif. 1996;29(1): 13-31. 
[8] Lee NP, Leung KW, Wo JY, Tam PC, Yeung WS, Luk JM. Blockage of testicular connexins induced apoptosis in rat seminiferous epithelium. Apoptosis. 2006;11(7): 1215-29.

[9] Russell LD, R. A. Ettlin, A. P. Sinha Hikim, and E. D. Clegg. Histological and histopathological evaluation of the testis. 1990 Philadelphia, PA: Cache River Press.

[10] Leblond CP, Clermont Y. Definition of the stages of the cycle of the seminiferous epithelium in the rat. Ann N Y Acad Sci. 1952;55(4): 548-73.

[11] Clermont Y. Kinetics of spermatogenesis in mammals: seminiferous epithelium cycle and spermatogonial renewal. Physiol Rev. 1972;52(1): 198-236.

[12] Graves D, Liu R, Oates T. Diabetes-enhanced inflammation and apoptosis - impact on periodontal pathosis. Periodontology. 2000; 45(1): 128-137.

[13] Elmore S. Apoptosis: A Review of Programmed Cell Death. Toxicol Pathol 2007 35: 495 .

[14] Liu G, Gong P, Bernstein LR, Bi Y, Gong S, Cai L. Apoptotic cell death induced by low-dose radiation in male germ cells: hormesis and adaptation. Crit Rev Toxicol. 2007; 37(7): 587-605.

[15] Koji T, Hishikawa Y. Germ cell apoptosis and its molecular trigger in mouse testes. Arch Histol Cytol. 2003; 66(1):1-16.

[16] Bozec A, Chuzel F, Chater S, Paulin C, Bars R, Benahmed M, Mauduit C. The mitochondrial-dependent pathway is chronically affected in testicular germ cell 
death in adult rats exposed in utero to anti-androgens. J Endocrinol. 2004;183(1): $79-90$.

[17] Vera Y, Diaz-Romero M, Rodriguez S, Lue Y, Wang C, Swerdloff RS, Sinha Hikim AP. Mitochondria-dependent pathway is involved in heat-induced male germ cell death: lessons from mutant mice. Biol Reprod. 2004;70(5):1534-40.

[18] Vydra N, Malusecka E, Jarzab M, Lisowska K, Glowala-Kosinska M, Benedyk K, Widlak P, Krawczyk Z, Widlak W. Spermatocyte-specific expression of constitutively active heat shock factor 1 induces HSP70i-resistant apoptosis in male germ cells. Cell Death Differ. 2006;13(2):212-22.

[19] Cai L, Chen S, Evans T, Deng DX, Mukherjee K, Chakrabarti S. Apoptotic germcell death and testicular damage in experimental diabetes: prevention by endothelin antagonism. Urol Res. 2000;28(5): 342-7.

[20] Zhao H, Xu S, Wang Z, Li Y, Guo W, Lin C, Gong S, Li C, Wang G, Cai L. Repetitive exposures to low-dose X-rays attenuate testicular apoptotic cell death in streptozotocin-induced diabetes rats. Toxicol Lett. 2010; 192(3):356-64.

[21] Zhao Y, Tan Y, Dai J, Li B, Guo L, Cui J, Wang G, Shi X, Zhang X, Mellen N, Li W, Cai L. Exacerbation of diabetes-induced testicular apoptosis by zinc deficiency is most likely associated with oxidative stress, p38 MAPK activation, and p53 activation in mice. Toxicol Lett. 2011; 200(1-2):100-6.

[22] Jiang X, Skibba M, Zhang C, Tan Y, Xin Y, Qu Y. The Roles of Fibroblast Growth Factors in the Testicular Development and Tumor. J Diabetes Res. 2013. 
[23] D E Johnson, P L Lee, J Lu, and L T Williams. Diverse forms of a receptor for acidic and basic fibroblast growth factors. Mol Cell Biol. 1990; 10(9): 4728-4736.

[24] Laslett AL, McFarlane JR, Risbridger GP. Developmental response by Leydig cells to acidic and basic fibroblast growth factor. J Steroid Biochem Mol Biol. 1997;60(3-4):171-9.

[25] Gerwins P, Sköldenberg E, Claesson-Welsh L. Function of fibroblast growth factors and vascular endothelial growth factors and their receptors in angiogenesis. Crit Rev Oncol Hematol. 2000; 34(3):185-94.

[26] Comerota AJ, Throm RC, Miller KA, Henry T, Chronos N, Laird J, Sequeira R, Kent CK, Bacchetta M, Goldman C, Salenius JP, Schmieder FA, Pilsudski R. Naked plasmid DNA encoding fibroblast growth factor type 1 for the treatment of end-stage unreconstructible lower extremity ischemia: preliminary results of a phase I trial. J Vasc Surg. 2002;35(5): 930-6.

[27] Nikol S, Baumgartner I, Van Belle E, Diehm C, Visoná A, Capogrossi MC, Ferreira-Maldent N, Gallino A, Wyatt MG, Wijesinghe LD, Fusari M, Stephan D, Emmerich J, Pompilio G, Vermassen F, Pham E, Grek V, Coleman M, Meyer F. Therapeutic angiogenesis with intramuscular NV1FGF improves amputation-free survival in patients with critical limb ischemia. Mol Ther. 2008;16(5): 972-8.

[28] Cheng H, Liao KK, Liao SF, Chuang TY, Shih YH. Spinal cord repair with acidic fibroblast growth factor as a treatment for a patient with chronic paraplegia. Spine (Phila Pa 1976). 2004; 29(14). 
[29] Xie L, Zhang M, Dong B, Guan M, Lu M, Huang Z, Gao H, Li X. Improved refractory wound healing with administration of acidic fibroblast growth factor in diabetic rats. Diabetes Res Clin Pract. 2011; 93(3):396-403

[30] Wang W, Lin S, Xiao Y, Huang Y, Tan Y, Cai L, Li X. Acceleration of diabetic wound healing with chitosan-crosslinked collagen sponge containing recombinant human acidic fibroblast growth factor in healing-impaired STZ diabetic rats. Life Sci. 2008; 82(3-4):190-204.

[31] Wu X, Su Z, Li X, Zheng Q, Huang Y, Yuan H. High-level expression and purification of a nonmitogenic form of human acidic fibroblast growth factor in Escherichia coli. Protein Expr Purif. 2005; 42: 7-11.

[32] McMahon M, Itoh K, Yamamoto M, Hayes JD. Keap1-dependent proteasomal degradation of transcription factor Nrf2 contributes to the negative regulation of antioxidant response element-driven gene expression. J Biol Chem. 2003; 278(24):21592-21600.

[33] Jiang X, Zhang C, Xin Y, Huang Z, Tan Y, Huang Y, Wang Y, Feng W, Li X, Li W, Qu Y, Cai L. Protective effect of FGF21 on type 1 diabetes-induced testicular apoptotic cell death probably via both mitochondrial- and endoplasmic reticulum stress-dependent pathways in the mouse model. Toxicol Lett. 2013; 219(1):65-76.

[34] Majewski N, Nogueira V, Bhaskar P, Coy PE, Skeen JE, Gottlob K, Chandel NS, Thompson CB, Robey RB, Hay N. Hexokinase-mitochondria interaction mediated by Akt is required to inhibit apoptosis in the presence or absence of Bax and Bak. Mol Cell. 2004; 16(5):819-30. 
[35] Schroder M, Kaufman RJ. The mammalian unfolded protein response. Annu Rev Biochem 2005; 74: 739-789.

[36] Tabas I, Ron D. Integrating the mechanisms of apoptosis induced by endoplasmic reticulum stress. Nat Cell Biol. 2011;13(3):184-90.

[37] Nakagawa T, Yuan J. Cross-talk between two cysteine protease families. Activation of caspase-12 by calpain in apoptosis. J Cell Biol. 2000; 150(4):887-894.

[38] Scorrano L, Oakes SA, Opferman JT, Cheng EH, Sorcinelli MD, Pozzan T, Korsmeyer SJ. BAX and BAK regulation of endoplasmic reticulum $\mathrm{Ca} 2+$ : a control point for apoptosis. Science. 2003; 300(5616):135-139.

[39] McCullough KD, Martindale JL, Klotz LO, Aw TY, Holbrook NJ. Gadd153 sensitizes cells to endoplasmic reticulum stress by down-regulating Bcl2 and perturbing the cellular redox state. Mol Cell Biol. 2001; 21(4):1249-1259.

[40] Li H, Zhu H, Xu CJ, Yuan J. Cleavage of BID by caspase 8 mediates the mitochondrial damage in the Fas pathway of apoptosis. Cell. 1998; 94(4):491-501.

[41] Breckenridge DG, Stojanovic M, Marcellus RC, Shore GC. Caspase cleavage product of BAP31 induces mitochondrial fission through endoplasmic reticulum calcium signals, enhancing cytochrome c release to the cytosol. J Cell Biol. 2003; 160(7):1115-1127.

[42] Shrilatha B, Muralidhara. Early oxidative stress in testis and epididymal sperm in streptozotocin-induced diabetic mice: its progression and genotoxic consequences. Reprod Toxicol. 2007; 23(4):578-587 
[43] Yamaguchi H, Wang HG. CHOP is involved in endoplasmic reticulum stressinduced apoptosis by enhancing DR5 expression in human carcinoma cells. J Biol Chem. 2004; 279(44):45495-45502.

[44] Finucane DM, Bossy-Wetzel E, Waterhouse NJ, Cotter TG, Green DR. Baxinduced caspase activation and apoptosis via cytochrome $\mathrm{c}$ release from mitochondria is inhibitable by Bcl-xL. J Biol Chem. 1999; 274(4):2225-2233

[45] Shiraishi H, Okamoto H, Yoshimura A, Yoshida H. ER stress-induced apoptosis and caspase-12 activation occurs downstream of mitochondrial apoptosis involving Apaf-1. J Cell Sci. 2006; 119(19):3958-3966. 


\title{
CURRICULUM VITA
}

\author{
Melissa Elizabeth Skibba
}

Email:

meskib01@louisville.edu

University of Louisville

Department of Pediatrics

570 S. Preston Street

Louisville, KY 40202

DOB:

Milwaukee, Wisconsin- August 19, 1990

\section{EDUCATION \& TRAINING:}

M.S. in Pharmacology and Toxicology

2012-present

University of Louisville

B.S. in Chemistry

2008-12

Carroll University

\section{AWARDS:}

Ohio Valley Society of Toxicology Best Graduate Student Presenting Poster, 2013

\section{PROFESSIONAL SOCIETIES:}

American Chemical Society

2010-present

Society of Toxicology

2012-present

\section{PUBLICATIONS:}

Research Papers:

1. Skibba, M., Zhang, C., Jiang, X., Ying, X, Cai, L. Preventive effect of nonmitogenic acidic fibroblast growth factor on diabetes-induced testicular cell death. Under Revision for Reproductive Toxicology, 2014. 
2. Jiang, X., Zhang, C., Zhang, Z., Feng, W., Skibba, M., Xin, Y., Cai, L. Protective effect of FGF21 on diabetes-induced testicular cell death is associated with upregulating AKT and AMPK/Sirt1/PGC-1 $\alpha$ pathways. Under Revision for Free Radical Biology and Medicine, 2014.

3. Zhang, C., Zhang, L., Chen, S., Feng, B., Bai, Y., Liang, G., Tan, Y., Shao, M., Skibba, M., Jin, L., Lu , X., Li, X., Chakrabarti, S., Cai, L. The prevention of diabetic cardiomyopathy by non-mitogenic acidic fibroblast growth factor is probably mediated by the suppression of oxidative stress and damage. PLoS One. 2013;8(12).

Abstracts:

1. Skibba, M., Xie, H., Stevenson, R., Hernandez-Santana, A., Graham, D. 2012. Detection of Nitric Oxide Release in Cell Medium through Surface Enhanced Resonance Raman Scattering. Abstract for poster presentation, National American Chemical Society Meeting, San Diego, CA.

2. Skibba, M., Zhang, C., Jiang, X., Cai, L. 2013. Preventive effect of non-mitogenic acidic fibroblast growth factor on diabetes-induced testicular cell death and atrophy. Abstract for poster presentation, Ohio Valley Society of Toxicology Meeting, Louisville, KY.

3. Skibba, M., Zhang, C., Jiang, X., Cai, L. 2013. Preventive effect of non-mitogenic acidic fibroblast growth factor on diabetes-induced testicular cell death and atrophy. Abstract for poster presentation, Research Louisville, Louisville, KY.

4. Skibba, M., Zhang, C., Jiang, X., Cai, L. 2014. Preventive effect of non-mitogenic acidic fibroblast growth factor on diabetes-induced testicular cell death and atrophy. Abstract for poster presentation, National Society of Toxicology Meeting, Phoenix, AZ.

5. Skibba, M., Zhang, C., Jiang, X., Cai, L. 2014. Preventive effect of non-mitogenic acidic fibroblast growth factor on diabetes-induced testicular cell death and atrophy. Abstract for poster presentation, The Kentucky Chapter of the American Physiology Society, Louisville, KY.

Reviews:

1. Jiang, X., Skibba, M., Zhang, C., Tan, Y., Xin, Y., and Qu, Y. The Roles of Fibroblast Growth Factors in the Testicular Development and Tumor. J. Diabetes Research 2013, 1-8. 


\section{NATIONAL MEETING PRESENTATIONS:}

2012 National American Chemical Society Meeting, San Diego, CA 2013 Ohio Valley Society of Toxicology Meeting, Louisville, KY.

2013 Research Louisville, Louisville, KY.

2014 National Society of Toxicology Meeting, Phoenix, AZ.

2014 The Kentucky Chapter of the American Physiology Society, Louisville, KY. 